\title{
Release of Candida albicans yeast antigens upon interaction with human neutrophils in vitro
}

\author{
CAROLYN ASHLEY, M. MORHART, R. RENNIE* and B. ZIOLA \\ Department of Microbiology, University of Saskatchewan, 107 Wiggins Road, Saskatoon, Saskatchewan S7N \\ $5 E 5$ and ${ }^{*}$ Medical Microbiology and Public Health, University of Alberta Hospital, Edmonton, Alberta T6G 2J2, \\ Canada
}

\begin{abstract}
Candida albicans is the leading cause of invasive candidosis. As conventional tests do not reliably detect invasive infection, attention has turned to the detection of $C$. albicans antigens circulating in blood. As antigen tests for invasive candidosis could be improved if $C$. albicans antigens released upon phagocytosis were defined, this study was undertaken to characterise antigens released during the interaction of yeasts and human neutrophils in vitro. An enzyme immunoassay developed previously to detect what were believed to be predominantly $C$. albicans cytoplasmic antigens in patients with invasive candidosis was used to follow the neutrophil-mediated release of yeast antigens. Serum opsonisation enhanced antigen release, which was rapid and essentially complete by $1 \mathrm{~h}$. When fresh $C$. albicans yeasts were added to medium from cultures of neutrophils plus yeasts or neutrophils plus latex beads, additional yeast antigens were released. Medium from neutrophils plus yeasts or from yeasts alone had similar immunoblot patterns with rabbit antibodies to a $C$. albicans cytoplasmic antigen preparation, with the reactive antigens generally being of higher mol. wt than the reactive antigens in the antigen mixture used for preparation of the antiserum. The two supernates also had similar immunoblot patterns with rabbit anti- $C$. albicans cell-wall mannan antibodies. These results suggest that yeast surface antigens are released quickly during phagocytosis by neutrophils. Detection of such yeast surface antigens, possibly together with selected yeast cytoplasmic antigens, should improve the sensitivity of $C$. albicans antigen assays.
\end{abstract}

\section{Introduction}

The opportunist fungal pathogen Candida albicans is the leading cause of invasive candidosis. Invasive candidosis is difficult to diagnose, firstly because clinical symptoms are often non-specific and, secondly, because conventional laboratory tests are not sufficiently sensitive. For example, culture of $C$. albicans from superficial body sites does not correlate well with infection. Moreover, blood cultures and tests to detect yeast-specific antibodies lack both sensitivity and specificity $[1,2]$. Clearly, better tests for the detection of invasive $C$. albicans infections are needed.

A recent report described an enzyme immunoassay (EIA) for the detection of what were presumed to be $C$. albicans cytoplasmic (CACP) antigens present in blood during invasive candidosis [3]. The EIA is

Received 7 Nov. 1996; revised version accepted 27 Jan. 1997.

Corresponding author: Professor B. Ziola. based on antisera raised against antigens in a $C$. albicans cytoplasmic extract prepared from disrupted yeast cells. Gel electrophoresis of CACP antigen showed five major proteins with mol. wt between $c$. $36 \mathrm{kDa}$ and $44 \mathrm{kDa}$. The EIA was shown to have a sensitivity of $70 \%$ and a specificity of $85-90 \%$ for patients at risk for invasive $C$. albicans infections.

If $C$. albicans cytoplasmic antigens are present in the circulation during invasive candidosis, it is thought to be due to antigen release following phagocytosis by neutrophils and other phagocytic cells $[2,4]$. However, the time course and nature of the antigens released remains largely undefined, as only a few $C$. albicans cytoplasmic antigens present in patient sera during invasive infection have been identified. These include enolase and a heat-shock protein $[5,6]$. It should also be noted that earlier work had indicated that $C$. albicans surface-accessible antigens, i.e., mannan or mannoproteins, are also present in the circulation of patients with invasive disease [7]. We believe that defining the $C$. albicans antigens that may circulate 
during invasive infection would lead to a more sensitive diagnostic test for this disease. Therefore an in-vitro approach was used to study the release of C. albicans antigens following the interaction of yeast cells with isolated human neutrophils.

\section{Materials and methods}

Yeasts

C. albicans clinical strain 60553 was propagated in liquid culture as described previously [3]. Freshly grown yeasts were washed twice at $4^{\circ} \mathrm{C}$ with a volume of sterile, phosphate-buffered saline (PBS; $20 \mathrm{mM}$ sodium phosphate buffer, $\mathrm{pH} 7.4$, and $140 \mathrm{mM} \mathrm{NaCl}$ ) equal to the original culture. Cells were resuspended in 0.5 volume of Hank's Balanced Salts Solution (pH 7.0-7.5; Gibco Laboratories) containing $20 \mathrm{mM}$ HEPES (Sigma) and $20 \mathrm{mM}$ sodium bicarbonate (buffered HBSS). Yeasts were counted in a haemocytometer, with $1 \mathrm{cfu}$ being a mother cell plus any attached buds. Yeasts were pre-opsonised according to the method of Solomkin et al. [8]. Cells were resuspended at $2 \times 10^{7} \mathrm{cfu} / \mathrm{ml}$ in buffered HBSS prewarmed to $37^{\circ} \mathrm{C}$ and containing autologous serum $10 \%$. After incubation at $37^{\circ} \mathrm{C}$ for $20 \mathrm{~min}$ on a rocking platform (four times $/ \mathrm{min}$ ), the cells were collected by centrifugation at $225 \mathrm{~g}$ for $5 \mathrm{~min}$ at $4^{\circ} \mathrm{C}$. The cells were washed once at $4^{\circ} \mathrm{C}$ with a volume of PBS equal to the opsonising medium and resuspended to $c \cdot 10^{8} \mathrm{cfu} / \mathrm{ml}$ in buffered HBSS. Viability was assessed with a trypan blue dye $0.1 \%$ solution [9]. Yeasts, pre-opsonised or not, were used in experiments at $10^{7} \mathrm{cfu} / \mathrm{ml}$.

\section{Neutrophils}

Peripheral blood was collected from donors who had given informed consent with venepuncture Vacutainer tubes (Becton Dickenson) containing EDTA $1.5 \mathrm{mg} / \mathrm{ml}$ as anticoagulant. A sample of blood was also collected without anticoagulant to provide autologous serum for yeast opsonisation. Neutrophils were separated from whole blood by differential centrifugation [10]. Four ml of anticoagulated blood were mixed at $4{ }^{\circ} \mathrm{C}$ with $16 \mathrm{ml}$ of isotonic $\mathrm{NH}_{4} \mathrm{Cl}$ solution in $50-\mathrm{ml}$ conical centrifuge tubes which were kept at $4^{\circ} \mathrm{C}$ for $15 \mathrm{~min}$ while red cell lysis occurred. White blood cells were collected by centrifugation at $160 \mathrm{~g}$ for $10 \mathrm{~min}$ at room temperature. The cells were resuspended in $10 \mathrm{ml}$ of calcium- and magnesium-free (CMF) buffered HBSS ( $\mathrm{pH} \mathrm{7-7.5)} \mathrm{and}$ transferred to $15-\mathrm{ml}$ conical tubes. Neutrophils were differentially pelleted by centrifugation at $55 \mathrm{~g}$ for $10 \mathrm{~min}$ at room temperature. Supernate was removed by suction and the neutrophils were resuspended in $5 \mathrm{ml}$ of CMF-buffered HBSS and again centrifuged (55 $\mathrm{g}, 5 \mathrm{~min}$ ). Neutrophils from all tubes were pooled in $0.75 \mathrm{ml}$ of CMF-buffered HBSS and counted manually in Türk's fluid. Control counts on some preparations were performed by the Haematology Laboratory, Royal University Hospital, Saskatoon.
Neutrophils were diluted in CMF-buffered HBSS to $10^{6} / \mathrm{ml}$ and held at $4^{\circ} \mathrm{C}$ until use $(1-8 \mathrm{~h}$ later $)$ Viability was assessed by trypan blue dye exclusion.

Sonicated neutrophils were used to test for neutrophil antigens which cross-react in the CACP antigen EIA. Neutrophils were sonicated at $10^{6} / \mathrm{ml}$ in $3 \mathrm{ml}$ of buffered HBSS containing autologous serum $10 \%$. Cells were disrupted with a Braunsonic 1510 ultrasonic homogeniser with a $14 \times 0.4-\mathrm{cm}$ probe and with sonic bursts of $350 \mathrm{~W}$ for $3 \times 15 \mathrm{~s}$ and $1 \times 30 \mathrm{~s}$. Between bursts, the tube was placed in ice for $1 \mathrm{~min}$. Microscopic examination after sonication showed no intact neutrophils.

\section{Latex beads}

Flouresbrite $^{\mathrm{TM}} 2.16-\mu \mathrm{m}$ plain latex beads (Polysciences Inc., Analychem Corporation) $\left(2 \times 10^{7} / \mathrm{ml}\right)$ were opsonised at $4^{\circ} \mathrm{C}$ for $\geqslant 12 \mathrm{~h}$ in buffered HBSS containing human immune serum globulin (Miles Canada Inc., Etobicoke, ON, Canada) $1 \mathrm{mg} / \mathrm{ml}$. Beads were kept in suspension by rocking (four times $/ \mathrm{min}$ ). They were then collected by centrifugation $(780 \mathrm{~g}$ at $4^{\circ} \mathrm{C}$ for $15 \mathrm{~min}$ ) and washed twice at $4^{\circ} \mathrm{C}$ with buffered HBSS equal to the original incubation volume. They were resuspended at $2 \times 10^{7} / \mathrm{ml}$ in buffered HBSS containing autologous serum $10 \%$. After incubation for $2 \mathrm{~h}$ at $37^{\circ} \mathrm{C}$ (rocking four times $/ \mathrm{min}$ ), the beads were collected by centrifugation, washed once and resuspended in buffered HBSS. To compensate for the smaller volume of the beads compared to yeast $\mathrm{cfu}$, the beads were used in experiments at $3 \times 10^{7} / \mathrm{ml}$.

\section{CACP antigen EIA}

The EIA developed to detect $C$. albicans cytoplasmic antigens in sera of patients with invasive candidosis [3] was used to detect $C$. albicans yeast antigens released upon interaction with neutrophils. Antigen was quantified by comparison with a standard curve constructed from CACP antigen prepared from C. albicans strain 60553 [3]. Throughout this work, antigen concentrations are expressed as [protein] $/ \mathrm{ml}$.

\section{Antisera}

Preparation of rabbit anti-CACP antigen antiserum was as described previously [3]. Rabbit anti-C. albicans cell-wall mannan antiserum was similarly prepared with $C$. albicans cell-wall mannan purified according to the method of Peat et al. [11]. Mouse antisera against two of the major CACP antigens (mol. wts 38 and $44 \mathrm{kDa}$ ) were prepared by immunising BALB/c mice with protein purified by two-dimensional polyacrylamide gel electrophoresis of CACP antigen [3]. Gel bands containing the $38-\mathrm{kDa}$ or the $44-\mathrm{kDa}$ protein were excised, dried and emulsified in PBS with a sterile glass rod. The immunising antigen was prepared in a MulsiChurn $^{\mathrm{TM}}$ (MulsiJet, Elmhurst, IL, USA) [12] and 
consisted of $c .1 \mu \mathrm{g}$ of protein in $0.25 \mathrm{ml}$ of PBS emulsified with $0.25 \mathrm{ml}$ of Freund's incomplete adjuvant, the emulsion was then dispersed by mixing with $0.5 \mathrm{ml}$ of Tween $802 \%$ in PBS [13]. Mice were immunised intraperitoneally with $1 \mathrm{ml}$ of antigen preparation. Mice received two booster injections at 2-week intervals and were terminally bled 3 weeks later. Antibody titres for the mouse antisera were determined by an antibody EIA in which adsorbed CACP antigen $(1.5 \mu \mathrm{g}$ in $200 \mu \mathrm{l}$ of PBS/well in a 96well plate) was the antibody-binding target and horseradish peroxidase (HRP)-conjugated Affinipure ${ }^{\mathrm{TM}}$ goat anti-mouse immunoglobulin $\operatorname{IgG}+\operatorname{IgM}(\mathrm{H}+\mathrm{L})$ antibodies (Jackson Immunoresearch Laboratories; Bio/ Can Scientific Inc., Mississauga, ON, Canada) were the indicator antibodies. Diluents and assay conditions paralleled successive steps of the CACP antigen EIA [3]. Titres of the mouse antisera were determined with an arbitrary cut-off of 0.2 units above background at an OD of $492 \mathrm{~nm}$.

\section{Time course of $C$. albicans antigen release}

A 1-ml mixture of cells and medium in a $1.5 \mathrm{ml}$ Eppendorf tube was used for each 15-min time point. Neutrophils were incubated with yeasts $(10 \mathrm{cfu} /$ neutrophil) at $37^{\circ} \mathrm{C}$ on a rocking platform (six times $/ \mathrm{min}$ ). Neutrophils and yeasts were also each incubated alone as controls. Culture medium was buffered HBSS with or without autologous serum $10 \%$. After a tube was removed, it was centrifuged at $8800 \mathrm{~g}$ for $3.5 \mathrm{~min}$ at room temperature and the supernate was saved. If a supernate was to be tested by CACP antigen EIA the following day, it was stored overnight at $4^{\circ} \mathrm{C}$; otherwise, storage was at $-20^{\circ} \mathrm{C}$.

\section{Extracellular release of neutrophil enzymes and metabolites}

One-ml mixtures of pre-opsonised $C$. albicans yeasts and neutrophils (10 cfu/cell), latex beads and neutrophils ( 30 beads/cell), neutrophils alone, and preopsonised yeasts alone were incubated at $37^{\circ} \mathrm{C}$ for $10 \mathrm{~min}$ in 1.5-ml Eppendorf tubes. After centrifugation $(8800 \mathrm{~g}$ for $3.5 \mathrm{~min})$ at room temperature, $0.9 \mathrm{ml}$ of supernate was removed and divided into two portions; $50 \mu \mathrm{l}$ of fresh, pre-opsonised yeasts $\left(0.5 \times 10^{7} \mathrm{cfu}\right)$ were added to one aliquot, while $50 \mu \mathrm{l}$ of CMFbuffered HBSS were added to the other as a negative control. After re-incubation at $37^{\circ} \mathrm{C}$ for $30 \mathrm{~min}$, yeast cells were removed by centrifugation as above. Supernates were stored at $-20^{\circ} \mathrm{C}$ until tested. C. albicans antigen was quantified before and after addition of fresh yeasts by the CACP antigen EIA.

\section{Immunoblotting}

Pre-opsonised yeasts were incubated with neutrophils $(10 \mathrm{cfu} / \mathrm{cell})$ on a rocking platform (six times $/ \mathrm{min}$ ) at $37^{\circ} \mathrm{C}$ in $15-$ or $50-\mathrm{ml}$ polypropylene tubes, containing
$10 \mathrm{ml}$ or $25-30 \mathrm{ml}$, respectively, of buffered HBSS. To provide control supernates, latex beads were incubated with neutrophils (30 beads/cell), and neutrophils and pre-opsonised yeasts were each incubated alone. Because neutrophils were prepared in CMF-medium, an equal volume of CMF-buffered HBSS was included in control tubes. Tubes were incubated for $1-2 \mathrm{~h}$ and centrifuged at $4^{\circ} \mathrm{C}$ at $280 \mathrm{~g}$ for $5 \mathrm{~min}$ (15-ml tubes) or $780 \mathrm{~g}$ for $10 \mathrm{~min}(50-\mathrm{ml}$ tubes $)$. Supernates were filtered through $0.45 \mu \mathrm{m}$ filters to remove remaining yeasts and neutrophils, and stored at $-20^{\circ} \mathrm{C}$ until used.

Equal volumes of test and control supernates (10$18 \mathrm{ml}$ ) from a given experiment were each concentrated to $c .1 \mathrm{ml}$ through a Diaflo ultrafilter in a $10-\mathrm{ml}$ concentrator (mol. wt cut-off 10000 ; Amicon). Concentrated supernates were transferred to Centricon-10 microconcentrators (Amicon, Toronto, ON, Canada). Diaflo filters were washed with $1 \mathrm{ml}$ of PBS and washes were transferred to microconcentrators, giving a total of $2 \mathrm{ml}$ for each supernate. Microconcentration and desalting (solvent exchange) with PBS in Centricon-10 microconcentrators were according to the supplier's protocol. Centrifugation was at $5000 \mathrm{~g}$ with an SS34 rotor in a Sorvall RC-5B centrifuge at $4^{\circ} \mathrm{C}$ for $80 \mathrm{~min}$. Final, desalted, concentrated supernates $(40-45 \mu \mathrm{l})$ were stored at $-20^{\circ} \mathrm{C}$ until use.

SDS-PAGE of concentrated supernates was performed under reducing conditions [14]. Electrophoresis was at $42 \mathrm{~mA}$ in a Hoefer SE600 water-cooled vertical slab gel unit (Hoefer Scientific Instruments; Fisher Scientific, Edmonton, AB, Canada) with stacking and separating gels of 4 and $10 \%$ acrylamide, respectively. The control lane contained $20 \mu \mathrm{g}$ of CACP antigen preparation. Equal volumes of desalted, concentrated supernates from the same experiment were added to the remaining lanes (antigen concentration was not determined).

Electrophoretic transfer was at $100 \mathrm{~V}$ for $1 \mathrm{~h}$ at $4^{\circ} \mathrm{C}$ in a TE Series Transphor Electrophoresis unit (Hoefer Scientific Instruments). Primary immunoblotting antibodies were rabbit anti-CACP antigen, or rabbit antiC. albicans cell-wall mannan polyvalent antiserum (diluted 1 in 150), or mouse monospecific antiserum (diluted 1 in 200). Indicator antibodies were either HRP-conjugated Affinipure ${ }^{\mathrm{TM}}$ donkey anti-rabbit IgG $(\mathrm{H}+\mathrm{L})$ antibodies (diluted 1 in 2000) or HRPconjugated Affinipure $^{\mathrm{TM}}$ goat anti-mouse $\operatorname{IgG}+\operatorname{IgM}$ $(\mathrm{H}+\mathrm{L})$ antibodies (diluted 1 in 1000) (Jackson Immunoresearch Laboratories). The colour development reagent was 4-chloro-1-naphthol.

\section{Results}

\section{Yeasts and neutrophils}

Yeasts were $100 \%$ viable in buffered HBSS; therefore, cellular breakdown had not begun before the initiation 
of experiments. One cfu was determined microscopically to contain from one to three cells (buds were considered as cells) with an average of 1.5 cells $/$ cfu. Occasionally, a single hyphal strand was observed; therefore, $\geqslant 99 \%$ of the cells were in yeast form in each experiment.

Neutrophils were obtained from blood by a differential centrifugation method which is rapid, yields neutrophil preparations of high purity and avoids potential adverse affects on neutrophil function [10]. An average neutrophil purity of $>70 \%$ was obtained. Other cells present were $\mathrm{T}$ and $\mathrm{B}$ lymphocytes (10$24 \%$ ), eosinophils $(2-11 \%)$ and monocytes $(3-6 \%)$. The use of CMF-buffered HBSS during neutrophil isolation and in experiments was essential to reduce white cell clumping. If used within $2.5 \mathrm{~h}$ after preparation, neutrophils were $100 \%$ viable before incubation with yeasts. When pre-opsonisation of latex beads or yeasts was required, typically $8 \mathrm{~h}$ elapsed between venepuncture and the start of the experiment, and c. $1.5 \%$ of all cells present had lost viability.

\section{Kinetics of phagocytosis}

During the incubation of yeasts or latex beads with neutrophils, $10-\mu \mathrm{l}$ portions were removed and yeasts or latex beads within neutrophils were counted by light microscopy at $400 \times$. Samples were taken every minute up to $5 \mathrm{~min}$, and then at $7.5,10,15,30$, 45 and $60 \mathrm{~min}$. Ingestion of yeasts or latex beads resulted in a distortion of neutrophil shape. In medium without serum, neutrophils showed little or no uptake of unopsonised yeasts or latex beads. In medium containing autologous serum $10 \%$, phagocytosis was rapid, with yeasts clearly visible inside neutrophils within 2-3 min. By $15 \mathrm{~min}$, many neutrophils had ingested several yeasts. Phagocytosis of preopsonised yeasts was also followed, as pre-opsonised yeasts were used to generate supernates for immunoblotting (the use of pre-opsonised yeasts ensured that reasonably efficient phagocytosis by neutrophils occurred, yet serum proteins were not present to complicate SDS-PAGE analysis of released yeast antigens).

Phagocytosis of pre-opsonised yeasts, in a medium lacking serum, occurred more slowly. In a representative experiment, $30(49 \%)$ of 61 neutrophils had ingested 86 pre-opsonised yeasts after incubation for $1 \mathrm{~h}$. The number of phagocytosed yeasts ranged from one to six, with the average being 1.4 , representing $c$. $15 \%$ of the total yeasts. Neutrophils ingested more pre-opsonised latex beads than pre-opsonised yeasts, as after incubation for $1 \mathrm{~h}, 21(70 \%)$ of 30 neutrophils had ingested at least one latex bead. The number of latex beads/neutrophil ranged from two to nine, with an average of three.
Time course and quantities of C. albicans antigen released

The largest release of $C$. albicans antigen occurred when yeasts were incubated with neutrophils in serum $10 \%$. Considerable quantities of antigen were detected at $15 \mathrm{~min}$, and release reached a maximum at $1 \mathrm{~h}$ (Fig. 1). Antigen release from pre-opsonised yeasts was slower, at a lower level, and reached a maximum slightly later. Overall, an even lower level of antigen release occurred from unopsonised yeasts incubated with neutrophils in buffered HBSS. The average amount of $C$. albicans antigen released when autologous serum $10 \%$ was present in the incubation medium was 4.5 times the average quantity released from preopsonised yeasts and 12.5 times that released from unopsonised yeasts (Table 1). Finally, only a low level of antigen release occurred from yeasts incubated alone in medium containing serum $10 \%$. Release of antigens from pre-opsonised yeasts or unopsonised yeasts incubated alone in buffered HBSS without serum was similarly low (data not shown). Neutrophils release antigens that only minimally cross-react in the CACP antigen EIA, as values only slightly above background were obtained when this supernate was tested (Fig. 1). No additional reactivity was observed when supernate from sonicated neutrophils alone in buffered HBSS plus serum $10 \%$ was tested undiluted (data not shown).

\section{Degradation of yeasts by extracellular neutrophil metabolites}

It seemed unlikely that large amounts of $C$. albicans antigen could be released within $15 \mathrm{~min}$ from inside

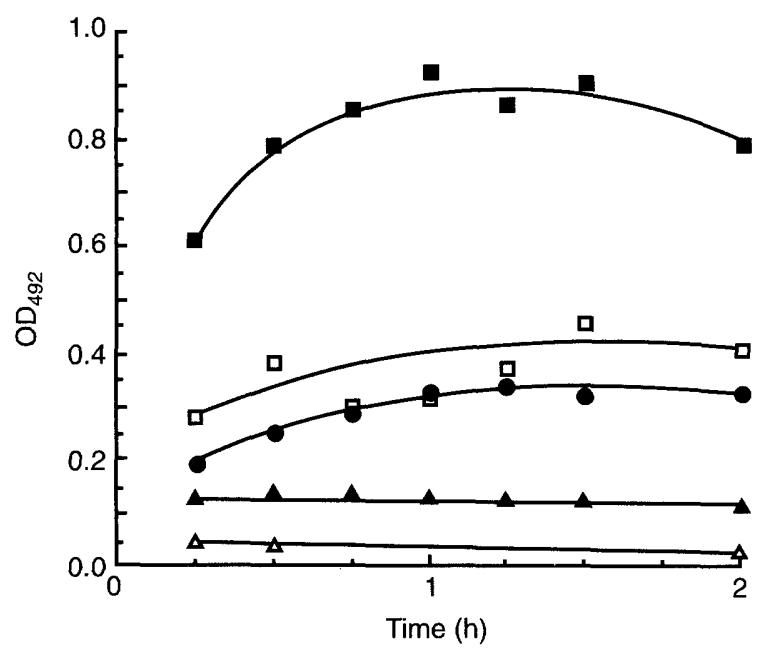

Fig. 1. C. albicans antigens released over $2 \mathrm{~h}$ detected by the CACP antigen EIA. Supernates were diluted 1 in 8 to avoid prozoning: further dilution gave progressively lower CACP antigen values. $\mathbf{a}$, Yeasts plus neutrophils in buffered HBSS containing $10 \%$ serum; $\square$, preopsonised yeasts plus neutrophils in buffered HBSS; yeasts plus neutrophils in buffered HBSS; $\boldsymbol{\Lambda}$, yeasts alone; or $\triangle$, neutrophils alone in buffered HBSS plus serum $10 \%$. Data shown are from a representative experiment and values have been corrected for the assay background of 0.240 . 
Table 1. Quantities of C. albicans antigen released from yeasts upon interaction with human neutrophils* under various conditions in vitro

\begin{tabular}{|c|c|c|}
\hline Supernate & Number tested & $\begin{array}{c}\text { Antigen released }(\mathrm{ng} / \mathrm{ml} \text {; average } \\
\text { and SE) }\end{array}$ \\
\hline \multicolumn{3}{|c|}{ Buffered HBSS $+10 \%$ autologous serum ${ }^{\dagger}$} \\
\hline Yeast plus neutrophil & 3 & $7900(3089)$ \\
\hline Yeast alone & 3 & $138(131)$ \\
\hline \multicolumn{3}{|c|}{ Pre-opsonised yeasts in buffered $\mathrm{HBSS}^{\ddagger}$} \\
\hline Yeast plus neutrophil & 6 & $1741(409)$ \\
\hline Yeast alone & 6 & $337(51)$ \\
\hline \multicolumn{3}{|c|}{ Buffered HBSS without serum ${ }^{\dagger}$} \\
\hline Yeast plus neutrophil & 5 & $634(173)$ \\
\hline Yeast alone & 5 & $215(79)$ \\
\hline
\end{tabular}

${ }^{*}$ Neutrophils were obtained from three normal volunteers.

${ }^{\dagger}$ Antigen release was monitored after incubation for $1 \mathrm{~h}$.

${ }^{\ddagger}$ In four cases, antigen release was monitored after incubation for $1 \mathrm{~h}$.

For the remaining two samples, incubation was for 1.5 and $2 \mathrm{~h}$ respectively.

Table 2. Release of solubilised $C$. albicans antigens by neutrophil metabolites

\begin{tabular}{lcccc}
\hline & \multicolumn{4}{c}{ C. albicans antigen $(\mathrm{ng} / \mathrm{ml}$; average and SE)* } \\
\cline { 2 - 5 } $\begin{array}{l}\text { Cells in } \\
\text { initial incubation }\end{array}$ & $\begin{array}{c}\text { Number of } \\
\text { tests }\end{array}$ & $\begin{array}{c}\text { Initial } \\
\text { supernate }\end{array}$ & $\begin{array}{c}\text { Number of } \\
\text { tests }\end{array}$ & $\begin{array}{c}\text { Final } \\
\text { supernate }\end{array}$ \\
\hline $\begin{array}{l}\text { Pre-opsonised yeasts plus } \\
\text { neutrophils }\end{array}$ & 7 & $547(61)$ & 8 & $1130(58)$ \\
$\begin{array}{l}\text { Latex beads plus } \\
\text { neutrophils }\end{array}$ & 8 & 0 & 4 & $1290(124)$ \\
$\begin{array}{l}\text { Neutrophils } \\
\text { Pre-opsonised yeasts }\end{array}$ & 8 & 0 & 3 & $485(28)$ \\
\hline
\end{tabular}

*After incubation for $10 \mathrm{~min}$ in buffered HBSS, pre-opsonised yeasts and neutrophils, latex beads and neutrophils, pre-opsonised yeasts alone, or neutrophils alone were removed. Fresh, preopsonised yeasts were added to the recovered supernate and incubated for a further $30 \mathrm{~min}$. Antigen levels were assigned by EIA with CACP antigen to create a standard curve [3].

the neutrophil phagolysosomes (Fig. 1). Table 2 shows that during phagocytosis, neutrophils released metabolites which could solubilise antigens from non-phagocytosed yeasts. A further $583 \mathrm{ng}$ of $C$. albicans antigen $/ \mathrm{ml}$ was released when fresh yeasts were incubated in a supernate derived from a short incubation of yeasts with neutrophils. When fresh yeasts were incubated in a supernate from a comparable incubation of latex beads plus neutrophils, a further $1290 \mathrm{ng}$ of $C$. albicans antigen $/ \mathrm{ml}$ was released. Centrifugation conditions used to obtain initial supernates $(8800 \mathrm{~g}, 3.5 \mathrm{~min})$ also resulted in a release of neutrophil metabolites in the absence of phagocytosis, as incubation of fresh yeasts in supernate from neutrophils alone released an additional $485 \mathrm{ng}$ of C. albicans antigen $/ \mathrm{ml}$. In comparison, only $109 \mathrm{ng} / \mathrm{ml}$ was released when yeasts were incubated in a supernate from yeasts initially incubated alone.

\section{Mol. wt of C. albicans antigens released}

Whether $C$. albicans antigens were released in degraded form was determined by using the CACP antigen EIA to quantify the amount of antigen able to pass through a concentration filter with a mol. wt cutoff of $10 \mathrm{kDa}$. Only $11 \%$ of EIA-reactive material in the supernate after incubation of pre-opsonised yeasts plus neutrophils for $1 \mathrm{~h}$ was $<10 \mathrm{kDa}$ in size.

\section{Immunoblotting}

Because of the small amount of $C$. albicans antigen released into the supernate following neutrophil phagocytosis of pre-opsonised yeasts, it was necessary to concentrate the supernates before immunoblotting. Immunoblotting with rabbit anti-CACP antigen antiserum highlighted a greater proportion of higher mol. wt immunoreactive material in yeast plus neutrophil supernate than in the CACP antigen preparation (Fig. 2). These immunoreactive components appeared as heavy, diffuse bands with mol. wts between 50 and $100 \mathrm{kDa}$. Antigens of the same mol. wt range appeared when the yeast supernate was tested, but fewer antigens were stained and the staining was less intense. A number of bands corresponding to cross-reactive neutrophil antigens appeared in the lane corresponding to latex bead plus neutrophil supernate. Immunoblotting with rabbit antiserum to $C$. albicans cell-wall mannan (Fig. 3) highlighted the same range of high mol. wt antigens in yeast plus neutrophil supernate as observed with rabbit anti-CACP antigen antiserum (Fig. 2), although a different banding pattern was 


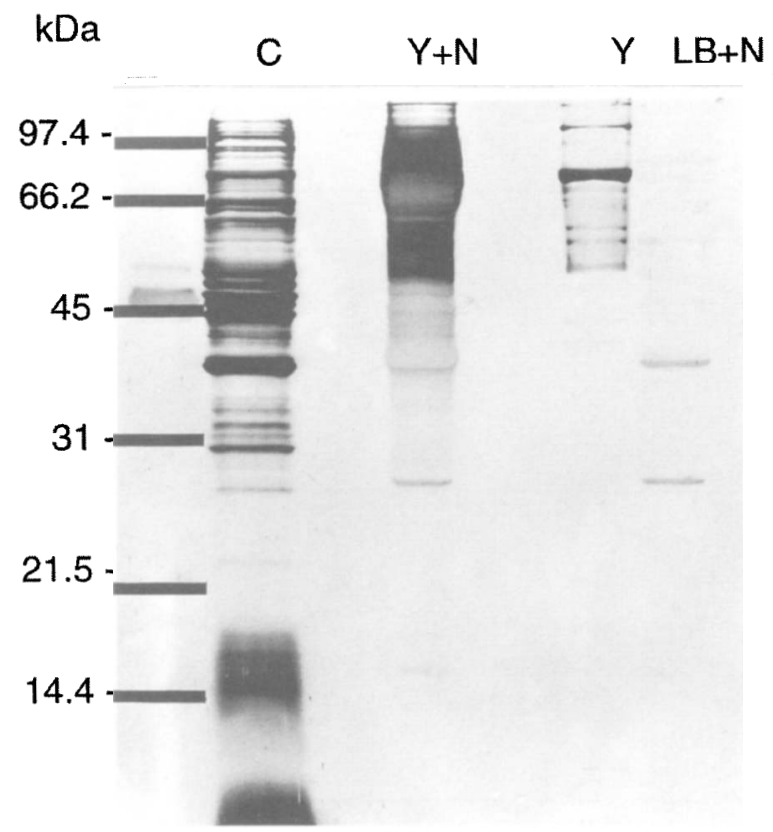

Fig. 2. Immunoblot of concentrated supernates with rabbit anti-CACP antigen antiserum. $\mathbf{C}, \mathrm{CACP}$ antigen control. Equal volumes of concentrated supernates obtained after incubation for $1.5 \mathrm{~h}$ were added to remaining lanes: $\mathbf{Y}+\mathbf{N}$, pre-opsonised yeasts plus neutrophils; $\mathbf{Y}$, yeasts alone; $\mathbf{L B}+\mathbf{N}$, latex beads plus neutrophils.

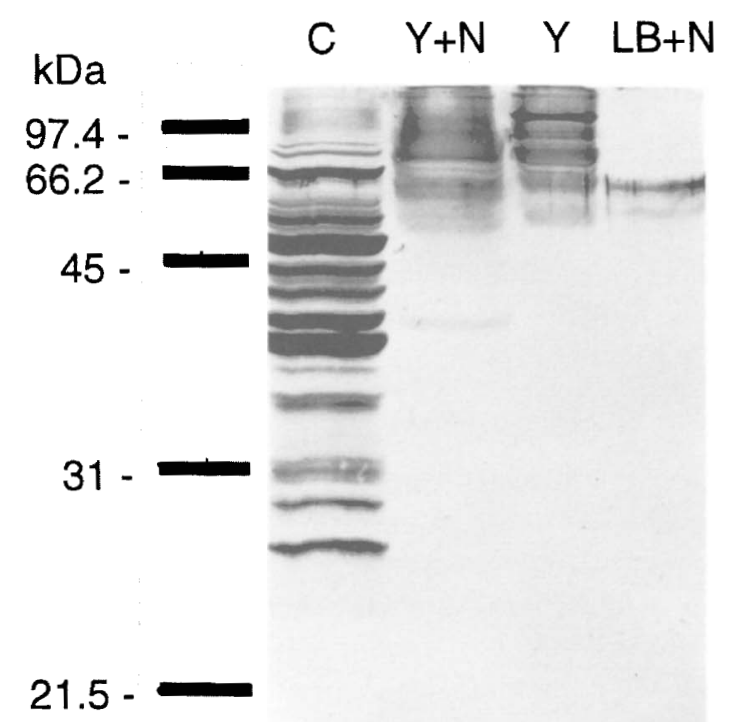

Fig. 3. Immunoblot of concentrated supernates with rabbit antiserum to $C$. albicans cell-wall mannan. Lanes and experimental conditions were as in Fig. 2. present. Again, some cross-reacting material was observed in the supernate of latex beads incubated with neutrophils.

Concentrated supernates were also immunoblotted with mouse monospecific antisera against the 38and 44-kDa CACP antigens (Fig. 4). The EIAdetermined titre of antiserum from a single mouse immunised with the $38-\mathrm{kDa}$ antigen was 1 in 800 , while titres of antisera from three mice immunised with the $44-\mathrm{kDa}$ antigen were 1 in 3200,1 in 6400 and 1 in 12800 . Blotting with a pre-immune serum pool failed to reveal antigens in either the CACP antigen preparation or the concentrated supernates (data not shown). Immunoblotting with the mouse

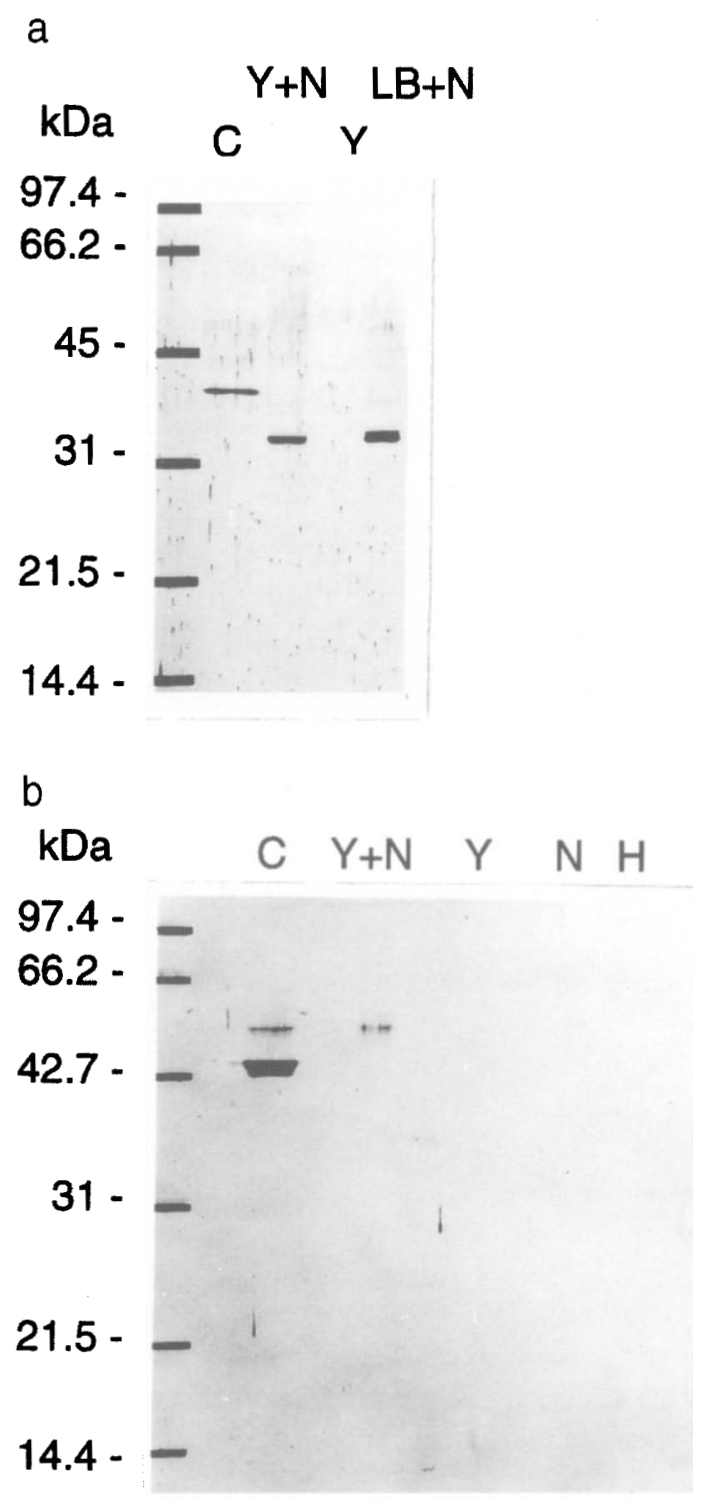

Fig. 4. Immunoblots with mouse monospecific antiserum against the $38-\mathrm{kDa}$ (a) and $44-\mathrm{kDa}$ (b) $\mathrm{CACP}$ antigens. C, CACP antigen control. Equal volumes of concentrated supernate obtained after incubation for $1.5 \mathrm{~h}$ were added to the remaining lanes: $\mathbf{Y}+\mathbf{N}$, yeasts plus neutrophils; $\mathbf{Y}$, yeasts alone; $\mathbf{L B}+\mathbf{N}$, latex beads plus neutrophils; $\mathbf{N}$, neutrophils alone; $\mathbf{H}$, buffered HBSS. 
monospecific antiserum raised against the $38-\mathrm{kDa}$ antigen showed that this antigen was not present in yeast plus neutrophil supernate, although the expected band appeared in the CACP antigen (Fig. 4a). A lower mol. wt band appearing in the yeast plus neutrophil lane was probably a cross-reactive neutrophil antigen, as a band of similar mol. wt was also present in the latex bead plus neutrophil lane. Immunoblotting with pooled monospecific antisera raised against the 44$\mathrm{kDa}$ antigen showed binding with two antigens in CACP antigen; namely a 44-kDa major antigen and a $55-\mathrm{kDa}$ minor antigen (Fig. 4b). Only a 55-kDa antigen was present in yeast plus neutrophil supernate. No reactive antigens were present in yeast-alone or neutrophil-alone supernates.

\section{Discussion}

Although the neutrophil preparations in the present study contained low levels of contaminating $\mathrm{T}$ and $\mathrm{B}$ lymphocytes and eosinophils, these cells play only a minor role in the phagocytosis and killing of $C$. albicans compared to neutrophils $[15,16]$. Small numbers of monocytes were also present and these cells are efficient in the phagocytosis and killing of $C$. albicans yeasts [15-19]. However, as neutrophils comprised $>70 \%$ of the phagocytic cells in the preparations, it was expected that the majority of $C$. albicans antigens were released because of neutrophil action.

When serum was present in the medium, phagocytosis was rapid and yeasts were visible inside neutrophils within a few minutes. Evans [20] has shown that a single phagocytic event can occur in as little as $2 \mathrm{~s}$ once a yeast cell and a neutrophil are in contact in a medium containing serum. When equal numbers of yeasts and neutrophils are incubated together, virtually all yeasts are phagocytosed by $15 \mathrm{~min}[9,15]$. Furthermore, neutrophils can ingest $7-11$ yeasts/ neutrophil during a incubation for $1 \mathrm{~h}$ in a medium containing serum $10 \%[8,9,20-22]$. In the present system, neutrophils each ingested an average of 1.4 pre-opsonised yeasts, representing $c .15 \%$ of the total yeasts present. The fact that each neutrophil ingested only one or two pre-opsonised yeasts is probably because pre-opsonised yeasts were taken up more slowly than yeasts in the presence of serum, as a result of the washing step following opsonisation removing some opsonising serum factors from the yeast surface. It should also be noted that to ensure that phagocytosis was not limited by the number of yeasts present, a 10-fold excess of yeast cfu over neutrophils was used, resulting in a smaller percentage of yeasts being phagocytosed compared to the other studies discussed above.

When yeasts were incubated with neutrophils in a medium containing serum, substantial release of $C$. albicans antigen occurred within $15 \mathrm{~min}$ (Fig. 1). When pre-opsonised yeasts or untreated yeasts were used, release of $C$. albicans antigen was slightly slower and did not reach the same level as with serum present (Fig. 1; Table 1). However, in either case it seems unlikely that the rapid release of antigen observed could occur from yeasts within intact neutrophil phagolysosomes. An alternative scenario is that surface antigens were released both from yeasts being phagocytosed and from the large number of external yeasts not yet undergoing phagocytosis. Surface solubilisation of yeast antigens probably begins immediately upon initiation of phagocytosis, as neutrophil degranulation occurs, resulting in the release of granule contents into the developing phagolysosome [23]. At this point, neutrophil metabolites and quickly solubilised yeast surface antigens are free to diffuse into the surrounding medium. Furthermore, $20-40 \%$ of human neutrophil phagolysosomes containing ingested yeasts maintain an open channel to the outside of the cell [24-26]. This means that granule contents and solubilised antigens from ingested yeasts can continue to diffuse into the surrounding medium. This idea is supported by the finding that components of neutrophil oxygen-dependent reactions are detectable in the medium surrounding stimulated neutrophils $[27,28]$. These extracellular metabolites, including enzymes such as $\alpha$-mannosidase [29], can then cause release of surface antigens from surrounding unphagocytosed yeasts.

Immunoblotting of concentrated yeast plus neutrophil supernate with rabbit polyvalent anti-CACP antiserum gave heavy, diffuse bands in the same mol. wt range as antigens in a yeast-alone supernate (Fig. 2). The yeast cell wall contains glycoproteins, particularly mannoproteins, some of which are loosely bound, and can be released and detected in culture media [2, 30]. Consequently, it seemed likely that the densely staining, diffuse antigen bands in the yeast plus neutrophil supernate as well as corresponding bands in the yeast-only supernate were cell-wall mannoproteins. Immunoblotting with anti- $C$. albicans cell-wall mannan antiserum (Fig. 3) provided additional evidence for this. The fact that the anti-CACP antigen antiserum and anti-mannan antiserum were each able to stain the yeast surface strongly in an immunofluorescence assay (unpublished data) confirms that both antisera were able to recognise yeast surface antigens. It is perhaps not surprising that the rabbit antibodies raised against the CACP antigens can react with yeast surface antigens, as cytoplasmic extracts prepared from mechanically disrupted yeasts are known to contain cell-wall glycoproteins [2, 3]. This, taken together with the immunoblot and surface-reactivity results, suggests that mannoproteins were rapidly solubilised from the yeast cell wall when yeasts were incubated with neutrophils.

Mouse monospecific antisera against the 38- and 44- 
$\mathrm{kDa} \mathrm{CACP}$ antigens were also employed to obtain evidence that $C$. albicans surface antigens were released upon interaction with neutrophils. As both the $38-\mathrm{kDa}$ and $44-\mathrm{kDa}$ CACP antigens used to prepare the mouse antisera were derived from a yeast cytoplasmic extract that had been subjected to twodimensional SDS-PAGE [3], these antisera reacted well with the appropriate antigen in immunoblots of the control CACP antigen. Immunoblotting with antiserum raised against the $38-\mathrm{kDa}$ antigen revealed no bands in the yeast plus neutrophil supernate or in the yeast-only supernate which were unique compared to the neutrophil control supernate. In contrast, immunoblotting with the mouse antiserum to the 44$\mathrm{kDa}$ antigen highlighted a $55-\mathrm{kDa}$ antigen in only the yeast plus neutrophil supernate. As the antiserum to the $44-\mathrm{kDa}$ antigen also reacted with a $55-\mathrm{kDa}$ antigen present in minor amounts in the CACP antigen preparation, the $55-\mathrm{kDa}$ antigen may be a glycosylated version of the 44-kDa antigen, which is exported to and incorporated into the yeast cell wall, and released into the medium by neutrophil enzymes. If this is the case, the $55-\mathrm{kDa}$ antigen is apparently not loosely bound on the yeast cell surface, as this antigen was not detected in immunoblotting of the yeast-only supernate.

The results of the present study support the hypothesis that interaction of yeasts with neutrophils results in rapid release of surface antigens from yeasts that are being phagocytosed and from yeasts that are in the vicinity of activated neutrophils. The evidence that yeast surface antigens such as mannoproteins are actively released following interaction with neutrophils supports our contention that such antigens should be targeted by assays designed to detect yeast antigens in the peripheral blood of patents with invasive infection. In this regard, it should be noted that the rabbit antiCACP antibodies used in the EIA for invasive candidosis described earlier [3] probably already do this to an extent, as these antibodies can react with yeast surface antigens as shown by their ability to give a positive surface fluorescence antibody test with intact yeasts (unpublished data). Through defining the spectrum of yeast surface antigens released by neutrophil metabolites and recognised by the rabbit anti-CACP antiserum, we anticipate being able to develop a more sensitive and specific monoclonal antibody-based assay for the detection of $C$. albicans antigens released during invasive infection.

C. A. was the recipient of an Arthur Smythe Memorial Scholarship and a University of Saskatchewan Graduate Student Summer Scholarship.

\section{References}

1. Maksymiuk AW, Thongprasert S, Hopfer R, Luna M, Fainstein $\mathrm{V}$, Bodey GP. Systemic candidiasis in cancer patients. $\mathrm{Am} \mathrm{J}$ Med 1984; 77 Suppl 4D: 20-27.
2. Odds FC. Candida and candidosis, 2nd edn. London, Baillière Tindall. 1988.

3. Morhart M, Rennie R, Ziola B, Bow E, Louie TJ. Evaluation of enzyme immunoassay for Candida cytoplasmic antigens in neutropenic cancer patients. J Clin Microbiol 1994; 32: $766-776$.

4. Taschdjian CL, Toni EF, Hsu KC, Seelig MS, Cuesta MB, Kozinn PJ. Immunofluorescence studies of Candida in human reticuloendothelial phagocytes: implications for immunogenesis and pathogenesis of systemic candidiasis. Am $J$ Clin Pathol 1971; 56: $50-58$

5. Matthews R, Burnie J. Cloning of a DNA sequence encoding a major fragment of the 47 kilodalton stress protein homologue of Candida albicans. FEMS Microbiol Lett 1989; 51: 25-30.

6. Walsh TJ, Hathorn JW, Sobel JD et al. Detection of circulating Candida enolase by immunoassay in patients with cancer and invasive candidiasis. $N$ Engl $J$ Med 1991; 324: 1026-1031.

7. Lew MA, Siber GR, Donahue DM, Maiorca F. Enhanced detection with an enzyme-linked immunosorbent assay of Candida mannan in antibody-containing serum after heat extraction. $J$ Infect Dis 1982; 145: 45-56.

8. Solomkin JS, Mills EL, Giebink GS, Nelson RD, Simmons RL, Quie PG. Phagocytosis of Candida albicans by human leukocytes: opsonic requirements. $J$ Infect Dis 1978; 137: 30-37.

9. Leijh PCJ, van den Barselaar MT, van Furth R. Kinetics of phagocytosis and intracellular killing of Candida albicans by human granulocytes and monocytes. Infect Immun 1977; 17: $313-318$.

10. Eggleton P, Gargan R, Fisher D. Rapid method for the isolation of neutrophils in high yield without the use of dextran or density gradient polymers. J Immunol Methods 1989; 121: 105-113.

11. Peat S, Whelan WJ, Edwards TE. Polysaccharides of baker's yeast. Part IV. Mannan. J Chem Soc 1961; 1: 29-34.

12. Lockey SD, Berg RH. A syringe churn for making repository emulsions. Origins, principles and performance. Ann Allergy 1964; 22: 410-417.

13. Herbert WJ. Multiple emulsions: a new form of mineral-oil antigen adjuvant. Lancet 1965; 2771.

14. Laemmli UK. Cleavage of structural proteins during the assembly of the head of bacteriophage T4. Nature 1970; 227: $680-685$.

15. Lehrer RI, Cline MJ. Interaction of Candida albicans with human leukocytes and serum. $J$ Bacteriol 1969; 98: 996-1004.

16. Mims CA. Mims' pathogenesis of infectious disease, 4th edn. London, Academic Press. 1995: 75-77.

17. Decker T, Lohmann-Matthes M-L, Baccarini M. Heterogeneous activity of immature and mature cells of the murine monocytemacrophage lineage derived from different anatomical districts against yeast-phase Candida albicans. Infect Immun 1986; 54: $477-486$.

18. Domer JE, Carrow EW. Candidiasis. In: Cox RA (ed) Immunology of the fungal diseases. Boca Raton, CRC Press. 1989: 57-92.

19. Fromtling RA, Shadomy HJ. An overview of macrophagefungal interactions. Mycopathologia 1986; 93: 77-93.

20. Evans E. Kinetics of granulocyte phagocytosis: rate limited by cytoplasmic viscosity and constrained by cell size. Cell Motil Cytoskeleton 1989; 14: 544-551.

21. Louria DB, Brayton RG. Behaviour of Candida cells within leukocytes. Proc Soc Exp Biol Med 1964; 115: 93-98.

22. Pereira HA, Hosking CS. The role of complement and antibody in opsonization and intracellular killing of Candida albicans. Clin Exp Immunol 1984; 57: 307-314.

23. Newburger PE, Parmley RT. Neutrophil structure and function. In: Hoffman R, Benz EJ, Shattil SJ, Furie B, Cohen HJ (eds) Hematology. Basic principles and practice. New York, Churchill Livingstone. 1990; 522-533.

24. Cech P, Lehrer RI. Heterogeneity of human neutrophil phagolysosomes: functional consequences for candidacidal activity. Blood 1984; 64: 147-151.

25. Jacques YV, Bainton DF. Changes in $\mathrm{pH}$ within the phagocytic vacuoles of human neutrophils and monocytes. Lab Invest 1978; 39: 179-185.

26. Mandell GL. Intraphagosomal $\mathrm{pH}$ of human polymorphonuclear neutrophils. Proc Soc Exp Biol Med 1970; 134: 447-449. 
27. Test ST, Weiss SJ. Quantitative and temporal characterization of the extracellular $\mathrm{H}_{2} \mathrm{O}_{2}$ pool generated by human neutrophils. J Biol Chem 1984; 259: 399-405.

28. Weiss SJ, Klein R, Slivka A, Wei M. Chlorination of taurine by human neutrophils. Evidence for hypochlorous acid generation. $J$ Clin Invest 1982; 70: 598-607.

29. Marquis G, Garzon S, Montplaisir S, Strykowski H, Benhamou
N. Histochemical and immunochemical study of the fate of Candida albicans inside human neutrophil phagolysosomes. $J$ Leukoc Biol 1991; 50: 587-599.

30. Masler L, Sikl D, Bauer S, Sandula J. Extracellular polysaccharide-protein complexes produced by selected strains of Candida albicans (Robin) Berkhout. Folia Microbiol 1966; 11: $373-378$. 